\title{
ARD
}

\section{Effects of strontium ranelate on spinal osteoarthritis progression}

O Bruyere, D Delferriere, C Roux, J D Wark, T Spector, J-P Devogelaer, K Brixen, S Adami, J Fechtenbaum, S Kolta and J-Y Reginster

Ann Rheum Dis 2008;67;335-339; originally published online 26 Oct 2007; doi:10.1136/ard.2007.075572

Updated information and services can be found at:

http://ard.bmj.com/cgi/content/full/67/3/335

\section{These include:}

References This article cites 26 articles, 7 of which can be accessed free at: http://ard.bmj.com/cgi/content/full/67/3/335\#BIBL

1 online articles that cite this article can be accessed at: http://ard.bmj.com/cgi/content/full/67/3/335\#otherarticles

Rapid responses You can respond to this article at: http://ard.bmj.com/cgi/eletter-submit/67/3/335

Email alerting Receive free email alerts when new articles cite this article - sign up in the box at service the top right corner of the article

Topic collections Articles on similar topics can be found in the following collections

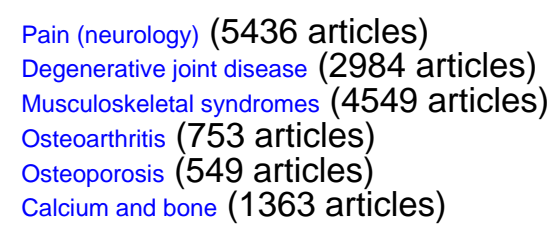

Notes

To order reprints of this article go to: http://journals.bmj.com/cgi/reprintform

To subscribe to Annals of the Rheumatic Diseases go to:

http://journals.bmj.com/subscriptions/ 


\title{
Effects of strontium ranelate on spinal osteoarthritis progression
}

\author{
0 Bruyere, ${ }^{1}$ D Delferriere, ${ }^{1}$ C Roux, ${ }^{2}$ J D Wark, ${ }^{3}$ T Spector, ${ }^{4}$ J-P Devogelaer, ${ }^{5}$ K Brixen, ${ }^{6}$ \\ S Adami, ${ }^{7}$ J Fechtenbaum, ${ }^{2}$ S Kolta, ${ }^{2}$ J-Y Reginster ${ }^{1}$
}

${ }^{1}$ Department of Epidemiology, Public Health and Health Economics, University of Liege, Liege, Belgium; ${ }^{2}$ Department of Rheumatology, Cochin Hospital, Paris, France; ${ }^{3}$ Department of Medicine and Bone \& Mineral Service, Royal Melbourne Hospital, Parkville, Australia;

${ }^{4}$ Department of Rheumatology, \& Genetic Epidemiology, St Thomas Hospital, Kings Collegue, London, UK; ${ }^{5}$ St-Luc University Hostpital, Université Catholique de Louvain, Brussels, Belgium; ${ }^{6}$ Department of Endocrinology, Odense University Hospital, Odense, Denmark; ${ }^{7}$ Department of Rheumatology Unit, Valeggio, Italy

Correspondence to: Prof Olivier BRUYERE, PhD, University of Liège, Department of Public Health, Epidemiology, and Health Economics, $\mathrm{CHU}$ Sart-Tilman, Bât B23, 4000 Liège, Belgium; olivier.bruyere@ ulg.ac.be

Accepted 13 October 2007 Published Online First 26 October 2007

\section{ABSTRACT}

Objective: The aim of this study was to determine whether a 3-year treatment with strontium ranelate could delay the progression of spinal osteoarthritis (OA).

Methods: This study was a post-hoc analysis of pooled data from the Spinal Osteoporosis Therapeutic Intervention (SOTI) and TReatment Of Peripheral OSteoporosis (TROPOS) trials performed on 1105 women with osteoporosis and concomitant radiological spinal OA at baseline, and for whom lumbar $x$-rays were available at baseline and over the 3-year treatment period. The presence and severity of osteophytes, disc space narrowing and sclerosis in the lumbar intervertebral spaces was graded according to a validated method, and an overall OA score was calculated for each intervertebral space. Back pain (measured on a five-point Likert scale only in SOTI) and health-related quality of life (SF-36 questionnaire) were assessed at baseline and after 3 years. Patients who suffered an incident or progressive vertebral fracture during the study were excluded from the analysis.

Results: The proportion of patients with worsening overall spinal OA score was reduced by $42 \%$ in the strontium ranelate group, compared with placebo (RR, $0.58 ; 95 \% \mathrm{Cl}, 0.42$ to $0.79 ; p=0.0005)$. Significantly more patients in the strontium ranelate group experienced an improvement in back pain after 3 years, compared with placebo ( $p=0.03$ ), while no significant difference was observed in terms of health-related quality of life between these patient groups.

Conclusions: The results of this post-hoc analysis suggest that strontium ranelate could reduce the progression of the radiographic features of spinal $\mathrm{OA}$ and back pain in women with osteoporosis and prevalent spinal $0 A$.

Osteoarthritis (OA) is a major cause of disability and is one of the most frequent musculoskeletal disorders. ${ }^{1}$ For decades, the traditional pharmacological management of $\mathrm{OA}$ has been mainly symptomatic, without the support of any welldocumented findings on the influence of treatment on disease duration and progression. Drugs with a favourable action on joint structure, which are therefore able to delay the progression of the disease, are termed structure-modifying drugs. ${ }^{23}$ During the last few years, several randomised controlled trials have been performed to assess the structure-modifying effect of various compounds, such as diacerein, ${ }^{4}$ glucosamine sulphate, ${ }^{56}$ chondroitin sulphate, ${ }^{78}$ and doxycycline. ${ }^{9}$ However, all these trials specifically addressed lower limb OA (ie, OA of the knee and/or hip), whereas very few data are currently available concerning spinal OA. ${ }^{10}$
Moreover, the pathophysiology of hip or knee OA differs from that of spinal OA. ${ }^{11}$

Lumbar disc degeneration is characterised by the presence of osteophytes, endplate sclerosis and disc space narrowing. There is no consensus as to whether this is a variant of general OA or a separate phenomenon, but lumbar spine disc degeneration is often referred to as spinal OA. ${ }^{12}$ As the severity of radiographic features of spinal OA correlates with increased back pain and decreased health-related quality of life, ${ }^{13}{ }^{14}$ any intervention able to delay the progression of spinal OA would be of great interest. Moreover, progression of $O A$ in the spine correlates significantly with progression at other clinical sites such as hand and knee. $^{15}$

Strontium ranelate is a new drug indicated for the treatment of postmenopausal osteoporosis, which has been proven to be effective in the reduction of vertebral and hip fractures. ${ }^{16} 17$ Previous studies have provided the preclinical basis for the in vivo testing of strontium ranelate in $O A$. In human normal and OA chondrocytes that are treated with or without interleukin $1 \beta$ (IL-1 $\beta$ ), strontium ranelate has been shown to stimulate the synthesis of type II collagen and proteoglycan. $^{18}$ Moreover, $10^{-3} \mathrm{M}$ strontium ranelate increased the stimulatory effect of insulin-like growth factor (IGF) on proteoglycan synthesis, but did not reverse the inhibitory effect of IL-1 $\beta .^{18}$ In a 3-year post-hoc analysis of the pool of Spinal Osteoporosis Therapeutic Intervention (SOTI) and TReatment Of Peripheral OSteoporosis (TROPOS) studies, strontium ranelate was also shown to significantly decrease, at all time points, the levels of urinary C-terminal telopeptides of type II collagen (u-CTX-II), a cartilage degradation biomarker with high tissue specificity, compared with placebo. ${ }^{19}$

The aim of the present study was to assess the efficacy of a 3-year treatment with strontium ranelate in delaying the clinical and structural progression of spinal $\mathrm{OA}$.

\section{METHODS}

The present study is a post-hoc analysis of the SOTI and TROPOS trials. ${ }^{16}{ }^{17}$ The design and methodology of these two studies have been described fully elsewhere. Briefly, ambulatory postmenopausal women were recruited in 11 European countries and in Australia into two prospective, randomised, double-blind, placebo controlled trials SOTI and TROPOS. Women were eligible for the SOTI trial if they were at least 50 years old, had been postmenopausal for at least 
5 years, had at least one prevalent vertebral fracture confirmed by spinal radiography and had a lumbar spine bone mineral density of $0.840 \mathrm{~g} / \mathrm{cm}^{2}$ or less. In the TROPOS trial, the eligibility criteria included a femoral neck bone mineral density of $0.600 \mathrm{~g} / \mathrm{cm}^{2}$ (corresponding to a T-score $<-2.5$ ); age 74 years or older; or age between 70 and 74 years with at least one additional risk factor for fracture. In both studies, patients received either $2 \mathrm{~g} /$ day strontium ranelate or placebo, for 3 years. Calcium and vitamin D supplementation was prescribed throughout the course of both trials, the dosage having been determined during a run-in period. All participants gave written informed consent before enrolment and both studies were approved by the relevant institutional review boards.

Lumbar spine vertebral radiographs were evaluated at baseline (month $0[\mathrm{M} 0]$ ) and after 3 years (month 36 [M36]) (or M24 in 579 patients for whom M36 radiographs were unavailable or not assessable). In SOTI and TROPOS, only lateral spine radiographs were available. A total of 4224 patients had both a baseline and post-baseline $x$-ray (fig 1). Four intervertebral spaces (L1-L2, L2-L3, L3-L4 and L4-L5) were examined for the presence and severity of anterior osteophytes (score 0-3), posterior osteophytes (score 0-3), joint space narrowing (score $0-3$ ) and sclerosis (score 0-1), and graded using an atlas according to the method of Lane et al. ${ }^{20}$ This enabled calculation of an overall OA score for each intervertebral space (graded from 0 to 2 ) as suggested in the original publication (table 1$).^{20}$

Of the 4224 patients, 2395 have all lumbar intervertebral spaces assessable (fig 1). All radiographs were read by the same person, who was blinded both to the treatment (strontium ranelate or placebo) and to the time sequence of radiograph acquisition ( $\mathrm{M} 0$ or $\mathrm{M} 36$ ). The reproducibility (test-retest of 40 radiographs over a 2-week interval) of these qualitative assessments was high, with a Kappa score between 0.85 and 0.92. The reproducibility of sclerosis assessment could not be

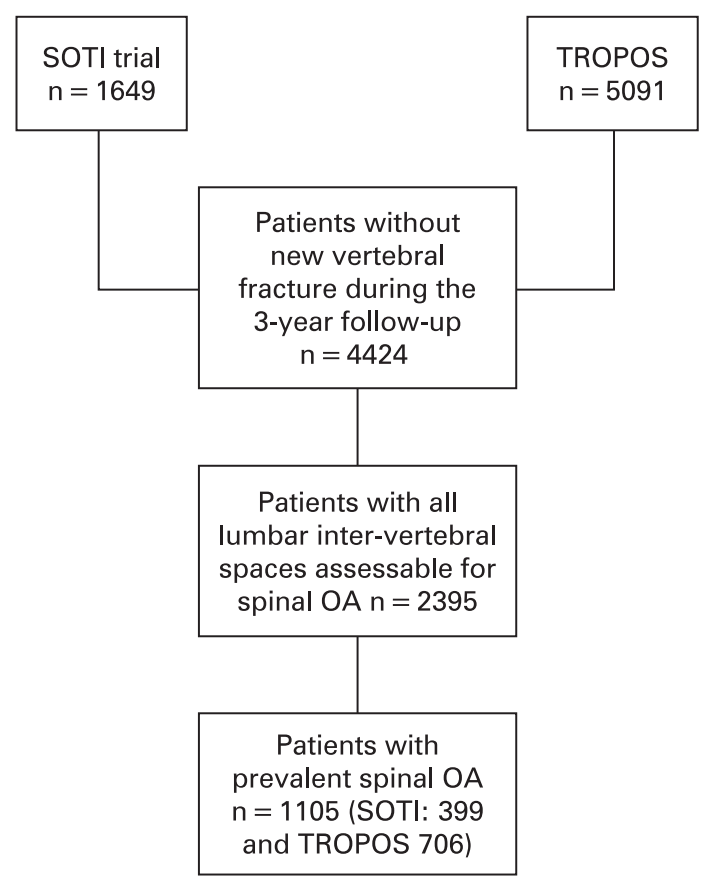

Figure 1 Study flowchart. OA, osteoarthritis; SOTI, Spinal Osteoporosis Therapeutic Intervention; TROPOS; TReatment Of Peripheral OSteoporosis.
Table 1 Individual lumbar disc degeneration features leading to the calculation of an overall osteoarthritis (OA) score

\begin{tabular}{ll}
\hline Lumbar disc degeneration & Overall OA score \\
\hline $\begin{array}{l}\text { Normal joint (0 for osteophytes, disc space } \\
\text { narrowing and sclerosis) }\end{array}$ & 0 \\
Mild (1) narrowing and/or mild (1) osteophytes & 1 \\
Moderate-severe (2-3) narrowing and/or & 2 \\
moderate-severe (2-3) osteophytes and/or & \\
presence (1) of sclerosis & \\
\hline
\end{tabular}

The numbers in parentheses correspond to grades of individual radiographic features.

evaluated because the number of patients with sclerosis was too small.

All patients were also asked to fill in the 36-item Short-Form health survey (SF-36). The SF-36 consists of 36 multiple-choice items comprising eight health domains that describe the overall health-related quality of life as reported by the subject. ${ }^{21}$ Four dimensions refer to physical health and four others to mental health. All subscales were scored using the Likert scale, with lower scores indicating a perception of poorer health, loss of function and presence of pain. The SF-36 has consistently shown high levels of reliability (test-retest and internal consistency reliability) and validity (content, concurrent, criterion-related, construct and predictive validity). ${ }^{21}$

As initially planned in the SOTI trial, patients were also asked to reply, at baseline and every 6 months, to one question related to back pain, using a five-point Likert scale: "During the past 4 weeks, have you had pain in the middle or upper part of your back?". The possibility of response was "not at all, no pain", "a little", "moderately", "quite a bit" and "a great deal". This question was part of the Qualiost questionnaire. ${ }^{22}$

\section{Statistical analysis}

Our post-hoc analysis was carried out in patients with and without prevalent vertebral fractures, who had prevalent spinal radiographic $O A$ (overall $O A$ score $\geqslant 1$ for each intervertebral space). However, as initially planned, patients who had suffered a new vertebral fracture or the worsening of a prevalent fracture during the trial were excluded (in order to avoid interference with the evaluation of spinal interspace and osteophyte formation). The primary efficacy outcome was defined as the proportion of patients in the strontium ranelate and placebo groups in whom the overall OA score increased by at least one grade of severity (in one or more intervtertebral spaces) during the 3-year follow-up period. The statistical difference between the two groups was assessed by the $\chi^{2}$ test. The secondary end point in our study was the difference in the proportion of patients, in the strontium ranelate and placebo groups, with a progression in the score of any single one of the radiographic features (ie, osteophytes, narrowing of disc space, or sclerosis), during the 3-year follow-up. Secondary analyses also included the analysis in the whole study population (with or without prevalent spine $\mathrm{OA}$ ) but also in patients with at least one intervertebral space with spinal OA. Changes in health-related quality of life scores after 3 years in both groups were assessed using the Mann-Whitney $U$ test. The proportion of patients having experienced an improvement in back pain of at least one point on the Likert scale was calculated in the strontium ranelate and placebo groups, and the statistical difference between the two groups was assessed by the $\chi^{2}$ test. Assessment of health-related quality of life was only performed in patients without new non-vertebral fractures $(n=880)$ in order to avoid any influence of such fractures on the overall 
Table 2 Baseline characteristics of the study population $(n=1105)$

\begin{tabular}{|c|c|c|c|}
\hline & $\begin{array}{l}\text { Strontium ranelate } \\
\text { Mean (SD) } \\
(\mathrm{n}=566)\end{array}$ & $\begin{array}{l}\text { Placebo } \\
\text { Mean (SD) } \\
(n=539)\end{array}$ & $\mathbf{p}$ \\
\hline Age: years & $72.9(6.5)$ & $73.1(7.4)$ & 0.55 \\
\hline BMI: kg/m² & $25.9(3.9)$ & $25.8(4.0)$ & 0.91 \\
\hline Lumbar BMD: $\mathrm{g} / \mathrm{cm}^{2}$ & $0.772(0.145)$ & $0.778(0.143)$ & 0.46 \\
\hline Hip BMD: $\mathrm{g} / \mathrm{cm}^{2}$ & $0.669(0.101)$ & $0.668(0.097)$ & 0.82 \\
\hline $\begin{array}{l}\text { Number of prevalent vertebral } \\
\text { fractures }\end{array}$ & $1.69(2.23)$ & $1.56(2.1)$ & 0.24 \\
\hline
\end{tabular}

$\mathrm{BMD}$, bone mineral density.

assessment of quality of life. Only the subgroup of patients form the SOTI trial replied to the question about back pain $(n=399)$. At least, we have looked at the proportion of patients, in each group, with new concomitant treatment taken for their OA.

\section{RESULTS}

Baseline characteristics of the study population are summarised in table 2. There were no statistical differences in the baseline characteristics between the strontium ranelate group and the placebo group.

At the end of the 3-year follow-up, $13.4 \%$ of patients experienced an increase in overall spinal OA score involving at least one intervertebral space. The proportion of patients with an overall OA score progression was 3.9\%, 3.7\%, 4.8\% and 3.6\% for the L1-L2, L2-L3, L3-L4 and L4-L5 intervertebral spaces, respectively.

After 3 years of study, only $9.9 \%$ in the strontium ranelate group experienced an increase in the overall $\mathrm{OA}$ score, versus $17.1 \%$ in the placebo group. The proportion of patients with an increase in the overall OA score was reduced by $42 \%$ in the strontium ranelate group, compared with placebo (RR, 0.58; $95 \%$ CI, 0.42 to $0.79 ; p=0.0005$ ) (fig 2).

After 3 years of treatment the number of patients in whom the disc space narrowing score worsened was significantly reduced by $33 \%$ in the strontium ranelate group, compared with placebo (RR 0.67; 95\% CI, 0.47 to $0.97 ; p=0.03$ ). There was also an absolute reduction in the proportion of patients with an increased severity of the osteophyte score in the strontium ranelate group, compared with placebo, but this finding did not reach statistical significance (table 3 ).

When our analysis is performed in the whole study population (ie, with or without prevalent spine $\mathrm{OA}$; $\mathrm{n}=2395), 29.5 \%$ in the strontium ranelate group experienced an increase in the overall spinal OA score after 3 years, versus

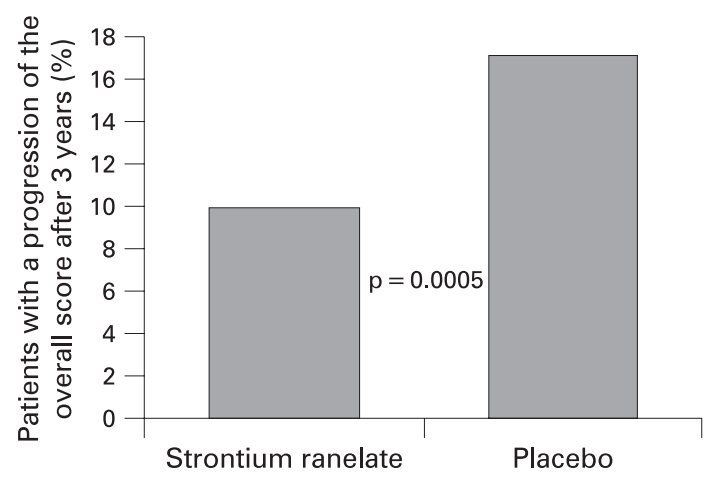

Figure 2 The percentage of patients with an increase in the overall score after 3 years' follow-up among the whole study population.
Table 3 Percentage of patients with worsening of osteoarthritis (OA) grading $(n=1105)$

\begin{tabular}{|c|c|c|c|c|}
\hline & $\begin{array}{l}\text { Strontium } \\
\text { ranelate } \\
n=566(\%)\end{array}$ & $\begin{array}{l}\text { Placebo } \\
n=539(\%)\end{array}$ & $\mathbf{p}$ & RR $(95 \% \mathrm{CI})$ \\
\hline Overall score & 9.9 & 17.1 & 0.0005 & $\begin{array}{l}0.58 \\
(0.42 \text { to } 0.79)\end{array}$ \\
\hline $\begin{array}{l}\text { Disc space } \\
\text { narrowing }\end{array}$ & 7.9 & 11.8 & 0.03 & $\begin{array}{l}0.67 \\
(0.47 \text { to } 0.97)\end{array}$ \\
\hline $\begin{array}{l}\text { Anterior } \\
\text { osteophytes }\end{array}$ & 12.9 & 15.5 & 0.22 & $\begin{array}{l}0.84 \\
(0.63 \text { to } 1.12)\end{array}$ \\
\hline $\begin{array}{l}\text { Posterior } \\
\text { osteophytes }\end{array}$ & 1.4 & 2.6 & 0.16 & $\begin{array}{l}0.55 \\
(0.23 \text { to } 1.29)\end{array}$ \\
\hline Sclerosis & 0 & 0.2 & NA & NA \\
\hline
\end{tabular}

$31.8 \%$ in the placebo group. As a matter of fact, strontium ranelate was not able to significantly reduce, compared with placebo, the proportion of patients with an increase in the overall OA score $(p=0.23)$, disc space narrowing $(p=0.93)$ or anterior osteophytes $(p=0.43)$ or posterior osteophytes $(p=0.42)$. In patients with at least one intervertebral space with $\mathrm{OA}$, the proportion of patients with a progressive OA score was reduced by $9 \%$, compared with placebo, but these results did not reach statistical significance $(p=0.14)$. The same trends have been shown for disc space narrowing, and anterior and posterior osteophytes ( $p=0.78,0.23$ and 0.39 , respectively).

After 3 years of treatment, more patients from the strontium ranelate group (84 of 201; 41.8\%) experienced an improvement in back pain (decrease by at least one point on the Likert scale) compared with placebo (62 of 198; 31.3\%; $p=0.03$ ). Figure 3 show the change in the Likert scale in the placebo and the strontium ranelate group during the 3 years of follow-up. In the whole study population, no significant improvements were observed in any of the items of the SF-36 in the strontium ranelate group, compared with placebo ( $p$-value between 0.18 and 0.93). In particular, there were no changes in the Physical and Mental component scores $(p=0.74$ and $p=0.73$, respectively).

During the 3 years of follow-up, $10.5 \%$ of patients from the placebo group took a treatment related to their OA, compared

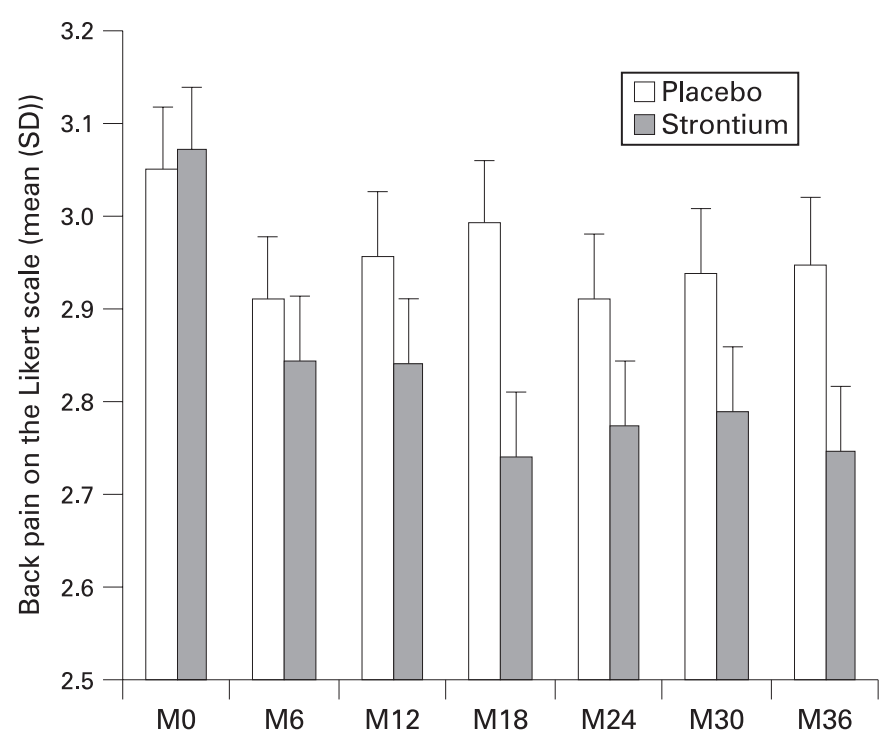

Figure 3 Evolution of back pain on the five-point Likert scale in the strontium ranelate and placebo groups during 3 years of follow-up. 
with $8.3 \%$ of the patients from the strontium ranelate group (RR $0.78 ; 95 \%$ CI, 0.55 to $1.12 ; \mathrm{p}=0.18$ ).

\section{DISCUSSION}

This post-hoc analysis suggests that strontium ranelate reduces radiographic spine $\mathrm{OA}$ progression in women with osteoporosis and prevalent spinal OA, with or without prevalent vertebral fractures. Concomitantly, a reduction in back pain was observed during the course of the 3-year treatment with strontium ranelate. These findings suggest that strontium ranelate may have symptom- and structure-modifying effects in women with osteoporosis and OA. New, prospective randomised controlled trials in patients with knee OA are currently ongoing to further confirm the potential structuremodifying effect of strontium ranelate.

Various methods have been proposed for assessing the severity of lumbar disc degeneration. Kellgren and Lawrence developed a grading scale. ${ }^{23}$ Lane et al sought to improve the moderate test-retest agreement and interrater agreement by defining radiographic indices of lumbar disc degeneration to evaluate the individual radiographic features of disc degeneration (ie, anterior osteophytes, posterior osteophytes, joint space narrowing and sclerosis). They were thus able to assign a summary grade derived directly from the evaluation of the selected radiographic features. ${ }^{20}$ The authors of the original study that validated this method also evaluated the two most frequently affected dorsal intervertebral spaces. ${ }^{20}$ In the present study, we used this method to assess lumbar spine OA. It should also be pointed out that the method of Lane et al and the views available did not allow assessment of intervertebral posterior articular or facet joints. ${ }^{20}$

Whether the occurrence of osteophytes and joint space narrowing are separate phenomena or not in the context of lumbar spine disc degeneration, remains unclear. ${ }^{12}$ In this study, we report a reduction in the progression of joint space narrowing with strontium ranelate, compared with placebo. Data are scarce with regard to therapies modifying the course of $\mathrm{OA},{ }^{4-10}$ especially in the spine, ${ }^{10}$ To the best of our knowledge, only one post-hoc analysis has shown that alendronate reduced spinal osteophyte formation in women with osteoporosis $(n=200)$, but no data on disc space narrowing were provided. ${ }^{10}$

Strontium ranelate is a drug registered for the treatment of osteoporosis. Other osteoporotic drugs have been tested for their structure-modifying properties in OA, but with conflicting results. ${ }^{102425}$ Alendronate has been reported to reduce spinal osteophyte formation, ${ }^{10}$ but two prospective placebo controlled studies found that risedronate failed to significantly reduce the radiographic progression of knee OA (ie, joint space narrowing). ${ }^{24} 25$

We hypothesise that the effect on joint space narrowing and osteophytes may be due to a direct effect of strontium ranelate on cartilage and bone resulting in endochondral ossification. Although the effects of strontium ranelate on bone have been well described, ${ }^{26} \mathrm{few}$ data are currently available on its effect on cartilage. ${ }^{18} 19$ In normal chondrocytes and chondrocytes with OA, cultured for $24-72$ hours in the presence or absence of strontium ranelate at concentrations ranging from $10^{-4}$ to $10^{-3} \mathrm{M}, 1 \mathrm{mM}$ strontium ranelate stimulated human cartilage matrix formation (type II collagen and proteoglycan synthesis), via a direct ionic effect, without stimulating chondroresorption processes. ${ }^{18}$ Measurement of u-CTX-II was carried out in a subset of 2617 postmenopausal women with osteoporosis from the phase III clinical trial TROPOS. ${ }^{19}$ A total of 1310 patients was assigned to active treatment for 3 years with strontium ranelate 2 g/day, while 1307 patients received placebo. During the 3 -year trial period, at all time points, there was a significant decrease in u-CTX-II of about $15-20 \%$ in the strontium ranelate-treated group, compared with placebo $(p<0.001) .{ }^{19}$

It should be pointed out that strontium ranelate seems to be less effective in patients without prevalent $O A$ at each intervertebral space suggesting that this drug could not be considered as a preventive treatment of incident spinal OA.

Our study did not show any significant improvement in health-related quality of life in patients taking strontium ranelate compared with placebo. However, it should be emphasised that the SF-36 questionnaire used in this study was a general questionnaire not OA-specific. The SOTI and TROPOS trials were initially designed to assess the effect of strontium ranelate on fracture incidence. As a consequence, no specific $O A$ questionnaires were used. The only question relating, at least in part, to OA symptoms was the "back pain" question. However, this question was not specifically restricted to the lumbar spine. Moreover, this question was only used in the SOTI trial and not addressed to the whole study population. Nevertheless, more patients in the strontium ranelate group experienced an improvement in back pain than in the placebo group even after excluding patients with incident fractures.

The study we report here has strengths as well as limitations. It was a post-hoc analysis of two prospective placebo controlled 3-year trials, in which the patients included were rigorously followed and radiograph acquisition was fully standardised. ${ }^{16}{ }^{17}$ The radiographs were read by a single trained person blinded to the treatment group and the time sequence of radiograph acquisition. However, no data on peripheral OA were available, nor did we assess thoracic spine OA. Moreover, the method of assessment of lumbar spine degeneration did not allow assessment of intervertebral posterior articular joints and lateral osteophytes or direct changes in the disc, which may also contribute to symptoms. At least, our results could not be extrapolated to all patients with lumbar OA as our study population consists of postmenopausal women with osteoporosis.

In conclusion, our findings suggest that strontium ranelate reduces the progression of radiographic spinal OA and back pain in women with osteoporosis and spinal OA. This study has implications not only in the potential treatment of chronic back pain, but also for progression of $\mathrm{OA}$ at other sites.

Funding: The study was supported by a research grant from Servier

Competing interests: None

\section{REFERENCES}

1. Lawrence RC, Helmick CG, Arnett FC, Deyo RA, Felson DT, Giannini EH, et al. Estimates of the prevalence of arthritis and selected musculoskeletal disorders in the United States. Arthritis Rheum 1998;41:778-99.

2. Recommendations for the Registration of Drugs used in the Treatment of Osteoarthritis. Group for the respect of ethics and excellence in science (GREES): osteoarthritis section. Ann Rheum Dis 1996;55:552-7.

3. Altman R, Brandt K, Hochberg M, Moskowitz R, Bellamy N, Bloch DA, et al. Design and conduct of clinical trials in patients with osteoarthritis: recommendations from a task force of the Osteoarthritis Research Society. Results from a workshop. Osteoarthritis Cartilage 1996:4:217-43.

4. Dougados M, Nguyen M, Berdah L, Mazieres B, Vignon E, Lequesne M. Evaluation of the structure-modifying effects of diacerein in hip osteoarthritis: ECHODIAH, a three-year, placebo-controlled trial. Evaluation of the chondromodulating effect of diacerein in OA of the hip. Arthritis Rheum 2001;44:2539-47.

5. Reginster JY, Deroisy R, Rovati LC, Lee RL, Lejeune E, Bruyere 0, et al. Long-term effects of glucosamine sulphate on osteoarthritis progression: a randomised, placebocontrolled clinical trial. Lancet 2001;357:251-6.

6. Pavelka K, Gatterova J, Olejarova M, Machacek S, Giacovelli G, Rovati LC. Glucosamine sulfate use and delay of progression of knee osteoarthritis: a 3-year, randomized, placebo-controlled, double-blind study. Arch Intern Med 2002;162:2113-23. 
7. Michel BA, Stucki G, Frey D, De Vathaire F, Vignon E, Bruehlmann P, et al. Chondroitins 4 and 6 sulfate in osteoarthritis of the knee: a randomized, controlled trial. Arthritis Rheum 2005; 52:779-86

8. Uebelhart D, Malaise M, Marcolongo R, DeVathaire F, Piperno M, Mailleux E, et al. Intermittent treatment of knee osteoarthritis with oral chondroitin sulfate: a one-year, randomized, double-blind, multicenter study versus placebo. Osteoarthritis Cartilage 2004:12:269-76.

9. Brandt KD, Mazzuca SA, Katz BP, Lane KA, Buckwalter KA, Yocum DE, et al. Effects of doxycycline on progression of osteoarthritis: results of a randomized, placebocontrolled, double-blind trial. Arthritis Rheum 2005;52:2015-25.

10. Neogi T, Nevitt M, Ensrud K, Bauer D, Felson DT. The effect of alendronate on progression of spinal osteophytes. Arthritis Rheum 2006;54(Suppl):S822.

11. Martel-Pelletier J, Lajeunesse D, Fahmi H, Tardif G, Pelletier JP. New thoughts on the pathophysiology of osteoarthritis: one more step toward new therapeutic targets. Curr Rheumatol Rep 2006:8:30-6.

12. Hassett G, Hart DJ, Manek NJ, Doyle DV, Spector TD. Risk factors for progression of lumbar spine disc degeneration: the Chingford Study. Arthritis Rheum 2003:48:31127.

13. Pye SR, Reid DM, Smith R, Adams JE, Nelson K, Silman AJ, et al. Radiographic features of lumbar disc degeneration and self-reported back pain. J Rheumatol 2004:31:753-8.

14. Borenstein D. Does osteoarthritis of the lumbar spine cause chronic low back pain? Curr Rheumatol Rep 2004;6:14-9.

15. Hassett G, Hart DJ, Doyle DV, March L, Spector TD. The relation between progressive osteoarthritis of the knee and long term progression of osteoarthritis of the hand, hip, and lumbar spine. Ann Rheum Dis 2006:65:623-8.

16. Meunier PJ, Roux C, Seeman E, Ortolani S, Badurski JE, Spector TD, et al. The effects of strontium ranelate on the risk of vertebral fracture in women with postmenopausal osteoporosis. N Engl J Med 2004;350:459-68.

17. Reginster JY, Seeman E, De Vernejoul MC, Adami S, Compston J, Phenekos C, et al. Strontium ranelate reduces the risk of nonvertebral fractures in postmenopausal women with osteoporosis: Treatment of Peripheral Osteoporosis (TROPOS) study. J Clin Endocrinol Metab 2005;90:2816-22.

18. Henrotin $\mathbf{Y}$, Labasse A, Zheng SX, Galais P, Tsouderos Y, Crielaard JM, et al Strontium ranelate increases cartilage matrix formation. J Bone Miner Res 2001;16:299-308

19. Alexanderson P, Karsdal M, Qvist P, Reginster JY, Christiansen C. Strontium ranelate reduces the urinary level of cartilage degradation biomarker CTX-II in postmenopausal women. Bone 2007;40:218-222.

20. Lane NE, Nevitt MC, Genant HK, Hochberg MC. Reliability of new indices of radiographic osteoarthritis of the hand and hip and lumbar disc degeneration. J Rheumatol 1993:20:1911-18.

21. McHorney CA, Ware JE Jr, Lu JF, Sherbourne CD. The MOS 36-item Short-Form Health Survey (SF-36): III. Tests of data quality, scaling assumptions, and reliability across diverse patient groups. Med Care 1994;32:40-66.

22. Marquis $\mathbf{P}$, Cialdella P, De la Loge $\mathbf{C}$. Development and validation of a specific quality of life module in post-menopausal women with osteoporosis: the QUALIOST. Qual Life Res 2001;10:555-66.

23. Kellgren JH, Lawrence JS. Radiological assessment of osteo-arthrosis. Ann Rheum Dis 1957:16:494-502

24. Spector TD, Conaghan PG, Buckland-Wright JC, Garnero P, Cline GA, Beary JF, et al. Effect of risedronate on joint structure and symptoms of knee osteoarthritis: results of the BRISK randomized, controlled trial [ISRCTN01928173]. Arthritis Res Ther 2005; 7:R625-33.

25. Bingham CO, Buckland-Wright JC, Garnero P, Cohen S, Dougados M, Adami S, et al Risedronate decreases biochemical markers of cartilage degradation but does not decrease symptoms or slow radiographic progression in patients with medial compartment osteoarthritis of the knee: results of the two-year multinational knee osteoarthritis structural arthritis study. Arthritis Rheum 2006;54:3494-507.

26. Jupsin I, Collette J, Henrotin Y, Bruyere 0, Sarlet N, Reginster JY. Strontium ranelate (Fujisawa/Servier). Curr Opin Investig Drugs 2005;6:435-44.

\section{FUNDING AVAILABLE FOR RESEARCH PROJECTS}

The Committee on Publication Ethics (COPE) has established a Grant Scheme to fund research in the field of publication ethics. The Scheme is designed to provide financial support to any member of COPE for a defined research project that is in the broad area of the organisation's interests, and specifically in the area of ethical standards and practice in biomedical publishing. The project should have a specific goal and be intended to form the kernel of a future publication.

A maximum sum of $£ 5000$ will be allocated to any one project, but applications for smaller sums are welcomed.

The terms and conditions of the Grant are as follows:

- At least one of the applicants must be a member of COPE.

- Calls for applications will be made twice a year with closing dates of 1 December and 1 June. An electronic version of the application form must be sent to the Administrator no later than $12 \mathrm{pm}$ (noon GMT) on the closing date for consideration by COPE Council.

- The application must contain a lay summary of the project, a definition of the question to be posed, sufficient methodological detail to allow assessment of the viability of the project, a clear timeline and a definition of the likely deliverables. A full justification for the sum requested must accompany the application.

- A report on the progress of the research should be presented within one year of the award and at the end of the project. The grant must be used within two years from the date of award, and balance sheets must be forwarded annually. These should be sent to the Administrator. Any remaining funds after two years must be returned.

- It is anticipated that the work stemming from the project will be presented at one of COPE's annual seminar meetings within 2-3 years of the award. Such data may also be published in peer-reviewed journals. Any publications or related presentations at meetings by the recipient emanating in part or whole from COPE's support should be duly acknowledged and copies sent to the Administrator.

Applications are reviewed by a COPE sub-committee. Applicants will be advised of a decision as soon as practicable after the deadline date.

An application form can be obtained by contacting Linda Gough, COPE administrator, at LGough@ bmj.com or 0207383 6602. For more information on COPE, see http://www.publicationethics.org.uk/

The closing date for receipt of applications is 1 December 2007 or 1 June 2008. 